\title{
Near Infrared Electrochemiluminescence of Rod-Shape 25-atom AuAg Nanoclusters that is Hundreds-fold Stronger than Ru(bpy) $)_{3}$ Standard
}

Shuang Chen, ${ }^{\dagger} \star$ Hedi Ma ${ }^{\star}$ Jonathan W. Padelford, ${ }^{\star}$ Wanli Qinchen, ${ }^{\dagger}$ Wei Yu, ${ }^{\dagger}$ Shuxin Wang,

${ }^{\dagger}$ Manzhou Zhu, ${ }^{*}{ }^{\dagger}$ Gangli Wang*, +

Department of Chemistry and Center for Atomic Engineering of Advanced Materials, Anhui University, Hefei, Anhui 230601, People's Republic of China

*Department of Chemistry, Georgia State University, Atlanta, Georgia 30302, United States

\section{List:}

Experiment section: Syntheses of $\mathrm{Ag}(\mathrm{I})$-thiolate complex, $\left[\mathrm{Au}_{11}\left(\mathrm{PPh}_{3}\right)_{8} \mathrm{Cl}_{2}\right]^{+}, \mathrm{Au}-\mathrm{PPh}_{3}$ nanoparticles, $\left[\mathrm{Ag}_{\mathrm{x}} \mathrm{Au}_{25-\mathrm{x}}\left(\mathrm{PPh}_{3}\right)_{10}\left(\mathrm{SC}_{2} \mathrm{H}_{4} \mathrm{Ph}\right)_{5} \mathrm{Cl}_{2}\right]^{2+}(\mathrm{x} \leq 12)$ and $\mathrm{Au}_{25}\left(\mathrm{SC}_{2} \mathrm{H}_{4} \mathrm{Ph}\right)_{18^{-}}$ nanoclusters.

Figure S1. UV-visible absorption spectrum of $\mathrm{Au}_{12} \mathrm{Ag}_{13}$.

Figure S2. Photon energy spectrum of $\mathrm{Au}_{12} \mathrm{Ag}_{13}$.

Figure S3. Differential pulse voltammogram of $\mathrm{Au}_{12} \mathrm{Ag}_{13}$.

Figure S4. Cyclic voltammogram of $1 \mathrm{mM} \mathrm{Au}{ }_{12} \mathrm{Ag}_{13}$.

Figure S5. Cyclic voltammogram of $\mathrm{Au}_{12} \mathrm{Ag}_{13}$ before and after bulk electrolysis at $+1.1 \mathrm{~V}$.

Figure S6. Cyclic voltammogram of $\mathrm{Ru}(\mathrm{bpy})_{3}, \mathrm{TPrA}$ and $\mathrm{Ru}(\mathrm{bpy})_{3}$ \& TPrA.

Figure S7. Cyclic voltammogram and ECL-potential curves of Ru(bpy) 3 -only.

Figure S8. Step ECL of $\left[\mathrm{Ag}_{\mathrm{x}} \mathrm{Au}_{25-\mathrm{x}}\left(\mathrm{PPh}_{3}\right)_{10}\left(\mathrm{SC}_{2} \mathrm{H}_{4} \mathrm{Ph}\right)_{5} \mathrm{Cl}_{2}\right]^{2+}(\mathrm{x} \leq 12)$ nanoclusters.

Figure S9. Step ECL of $\mathrm{Au}_{25}\left(\mathrm{SC}_{2} \mathrm{H}_{4} \mathrm{Ph}\right)_{18}{ }^{-}$nanoclusters. 


\section{Experiment section}

\section{Synthesis of $\mathbf{A g}(\mathbf{I})$-thiolate complex.}

$\mathrm{Ag}(\mathrm{I})-\mathrm{SPhC}_{2} \mathrm{H}_{4}$ compound was prepared following reported procedure. ${ }^{\mathrm{R} 1}$ Briefly, $1 \mathrm{~g} \mathrm{AgNO}_{3}$ (5.89 mmol) was first dissolved in mixed solvent of $1 \mathrm{ml} \mathrm{H}_{2} \mathrm{O}$ and $5 \mathrm{ml} \mathrm{EtOH}$ under ultrasonication. Then a mixture of $2 \mathrm{ml} \mathrm{Et} \mathrm{t}_{3} \mathrm{~N}$ containing $5.65 \mathrm{mmol}$ 2-phenylethanethiol $(0.78 \mathrm{~g})$ was added dropwise over 10 min under stirring forming a white turbid solution. The reaction proceeded for 30 minutes at room temperature. After centrifugation, the crude precipitate was washed with $\mathrm{EtOH}$ several times. The final white product $[\mathrm{Ag}(\mathrm{I})-$ thiolate] complex was collected after the removal of solvent under vacuum at room temperature.

\section{Synthesis of $\left[\mathrm{Au}_{11}\left(\mathrm{PPh}_{3}\right)_{8} \mathrm{Cl}_{2}\right]^{+}$.}

The synthesis of triphenylphosphine-stabilized Au clusters followed the recipe described in literature. ${ }^{\mathrm{R} 2}$ An aqueous solution of $\mathrm{HAuCl}_{4} \cdot 3 \mathrm{H}_{2} \mathrm{O}(0.4 \mathrm{ml}, 0.2 \mathrm{~g} / \mathrm{mL})$ was dissolved in $10 \mathrm{ml}$ of EtOH, and then solid triphenylphosphine $(0.16 \mathrm{~g}, 0.293 \mathrm{mmol})$ was added. The solution turned into a white suspension in $1 \mathrm{~min}$. a fresh solution of $\mathrm{NaBH}_{4}(0.019 \mathrm{~g}, 0.48 \mathrm{mmol}$, dissolved in $5 \mathrm{~mL}$ EtOH$)$ was added to the solution. After $\sim 2$ hours, the reaction mixture contained monodisperse $\mathrm{Au}_{11}$ clusters was obtained. The crude product was purified with DCM/Hex solvents.

\section{Synthesis of Phosphine-Protected Polydisperse Au Nanoparticles.}

$\mathrm{Au}$ nanoparticles capped with triphenylphosphine $\left(\mathrm{Au}-\mathrm{PPh}_{3}\right.$ nanoparticles) were prepared based on the recipe in the reference $\mathrm{R} 3$. $\mathrm{HAuCl}_{4} \cdot 3 \mathrm{H}_{2} \mathrm{O}\left(0.16 \mathrm{~g}, 0.4 \mathrm{mmol}\right.$, dissolved in $\left.5 \mathrm{ml} \mathrm{H}_{2} \mathrm{O}\right)$ and $\mathrm{TOABr}(0.254 \mathrm{~g}$, $0.465 \mathrm{mmol}$, dissolved in $10 \mathrm{ml}$ TOL) were mixed and stirred vigorously for 15 min to complete phase transfer process. After the aqueous phase was removed, $0.313 \mathrm{~g}(1.2 \mathrm{mmol}) \mathrm{PPh}_{3}$ was added to the TOL solution under moderate stirring. After $\sim 3$ minutes, $\mathrm{NaBH}_{4}(0.070 \mathrm{~g}, 1.85 \mathrm{mmol}$, dissolved in $5 \mathrm{ml} \mathrm{EtOH})$ was injected to the mixture. The solution immediately became dark. The reaction was allowed to proceed for 70 minutes at room temperature. The black products were washed several times with hexane and collected by rotary evaporation.

\section{Synthesis of $\left[\mathrm{Ag}_{\mathrm{x}} \mathrm{Au}_{25-\mathrm{x}}\left(\mathrm{PPh}_{3}\right)_{10}\left(\mathrm{SC}_{2} \mathrm{H}_{4} \mathrm{Ph}\right)_{5} \mathrm{Cl}_{2}\right]^{2+}(\mathrm{x} \leq 12)$ nanoclusters.}

$\left[\mathrm{Ag}_{\mathrm{x}} \mathrm{Au}_{25-\mathrm{x}}\left(\mathrm{PPh}_{3}\right)_{10}\left(\mathrm{SC}_{2} \mathrm{H}_{4} \mathrm{Ph}\right)_{5} \mathrm{Cl}_{2}\right]^{2+}(\mathrm{x} \leq 12)$ nanoclusters were synthesized with $\mathrm{Au}-\mathrm{PPh}_{3}$ nanoparticles and $\mathrm{Ag}(\mathrm{I})-\mathrm{SC}_{2} \mathrm{H}_{4} \mathrm{Ph}$ compound as precursors. Specifically, $\mathrm{PhC}_{2} \mathrm{H}_{4} \mathrm{~S}-\mathrm{Ag}(80 \mathrm{mg})$ and $\mathrm{Au}-\mathrm{PPh}_{3}$ nanoparticles $(75 \mathrm{mg})$ were added to the ethanol solution $(10 \mathrm{~mL})$ under vigorous stirring at $298 \mathrm{~K}$. After $6 \mathrm{~h}$, the product was dried in vacuum, washed several times with ethanol/hexane $(1: 3, \mathrm{~V} / \mathrm{V})$, a mixed solvent of DCM and Hex was used to extract clusters. The brownish-yellow solution was collected and mixed with an excess of $\mathrm{NaSbF}_{6}$. Insoluble products were collected on a filter and crystallized from a mixed solution of DCM and diethyl ether.

\section{Synthesis of $\mathrm{Au}_{25}\left(\mathrm{SC}_{2} \mathrm{H}_{4} \mathrm{Ph}\right)_{18^{-}}$nanoclusters.}

The $\mathrm{Au}_{25}\left(\mathrm{SC}_{2} \mathrm{H}_{4} \mathrm{Ph}\right)_{18}{ }^{-}$was prepared following the reported procedure in reference $\mathrm{R} 4$. Specifically, $\mathrm{HAuCl}_{4} \cdot 3 \mathrm{H}_{2} \mathrm{O}(0.1576 \mathrm{~g}, 0.4 \mathrm{mmol})$ dissolved in $5 \mathrm{~mL}$ nanopure water, and $\mathrm{TOABr}(0.2558 \mathrm{~g}, 0.47 \mathrm{mmol})$ dissolved in $10 \mathrm{~mL}$ toluene were added in a $25 \mathrm{~mL}$ tri-neck round bottom flask under vigorous stirring. After $15 \mathrm{~min}$ for the phase transfer to complete, the aqueous layer was removed, and the toluene solution 
of $\mathrm{Au}(\mathrm{III})$ was cooled down to $0{ }^{\circ} \mathrm{C}$ in an ice bath over a period of $30 \mathrm{~min}$ under magnetic stirring. $\mathrm{PhC}_{2} \mathrm{H}_{4} \mathrm{SH}(0.17 \mathrm{~mL})$ was added; stirring was reduced to a very low speed $(\sim 30 \mathrm{rpm})$ in 1 hour. A fresh aqueous solution of $\mathrm{NaBH}_{4}(0.1550 \mathrm{~g}$ in $7 \mathrm{~mL}$ ice-cold water) was quickly added all at once. The reaction was allowed to proceed overnight. EtOH and $\mathrm{ACN}$ were used to wash the products and extract the $\mathrm{Au}_{25}\left(\mathrm{SC}_{2} \mathrm{H}_{4} \mathrm{Ph}\right)_{18}{ }^{-}$respectively.

\section{Reference:}

R1. Li, G.; Lei, Z.; Wang, Q.-M., J. Am. Chem. Soc. 2010, 132, 17678-17679.

R2. Vollenbroek, F. A.; Bouten, P. C.; Trooster, P. J. M.; Van Den Berg, J. P.; Bour, J. J.; Inorg. Chem. 1978, 17, 1345.

R3. Qian, H.; Eckenhoff, W. T.; Bier, M. E.; Pintauer, T.; Jin, R., Inorg Chem 2011, 50 (21), 1073510739 .

R4. Zhu, M.; Lanni, E.; Garg, N.; Bier, M. E.; Jin, R. J. Am. Chem. Soc., 2008, 130, 1138.

\section{Supplementary Figures:}

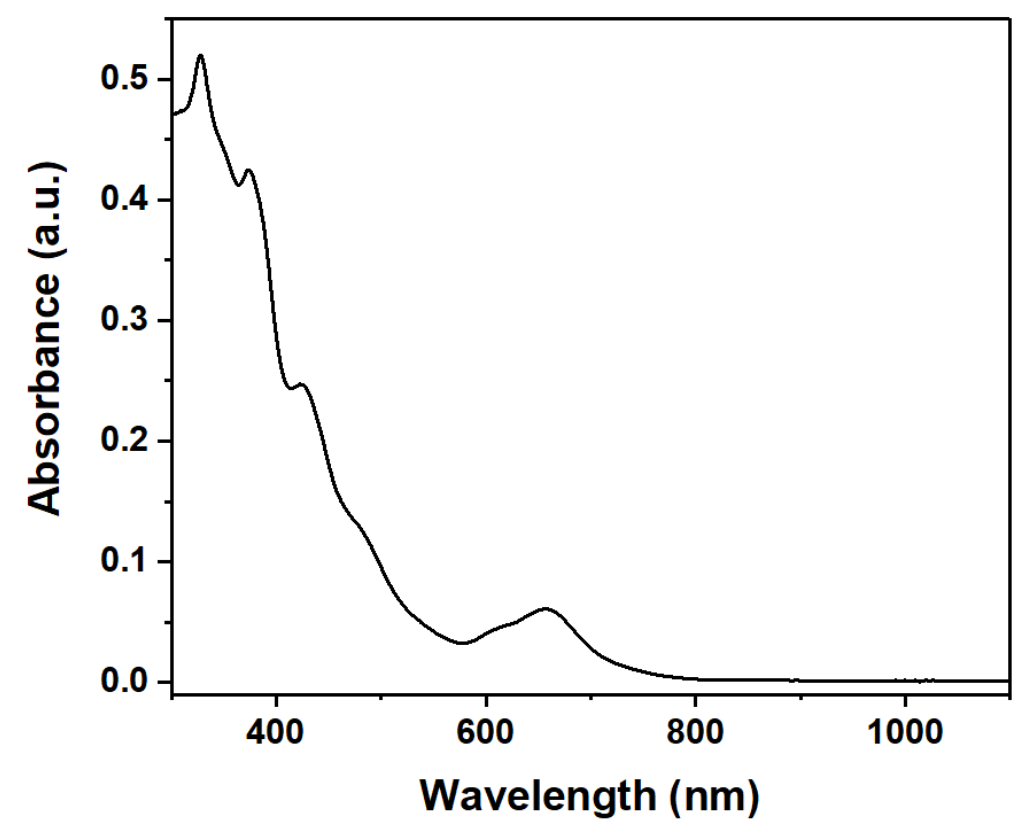

Figure S1. UV-vis spectrum of $\mathrm{Au}_{12} \mathrm{Ag}_{13}$ in 1:1 TOL/ ACN. 


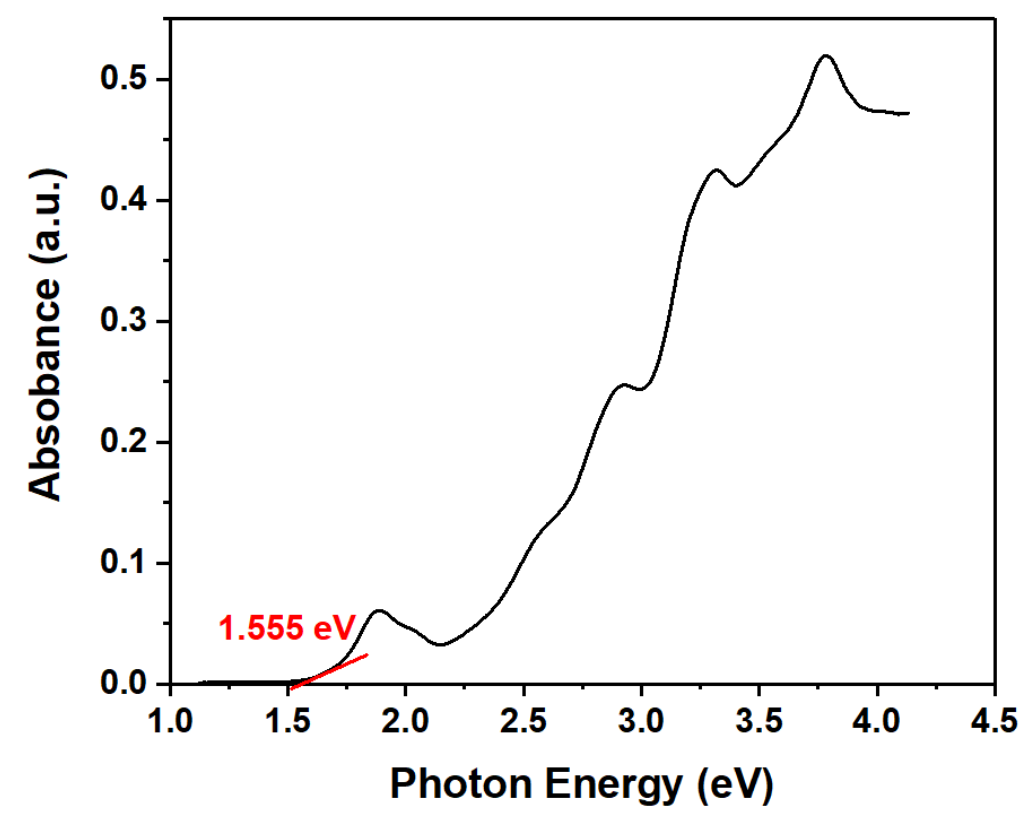

Figure S2. Photon energy spectrum of $\mathrm{Au}_{12} \mathrm{Ag}_{13}$. (replot of Figure S1)

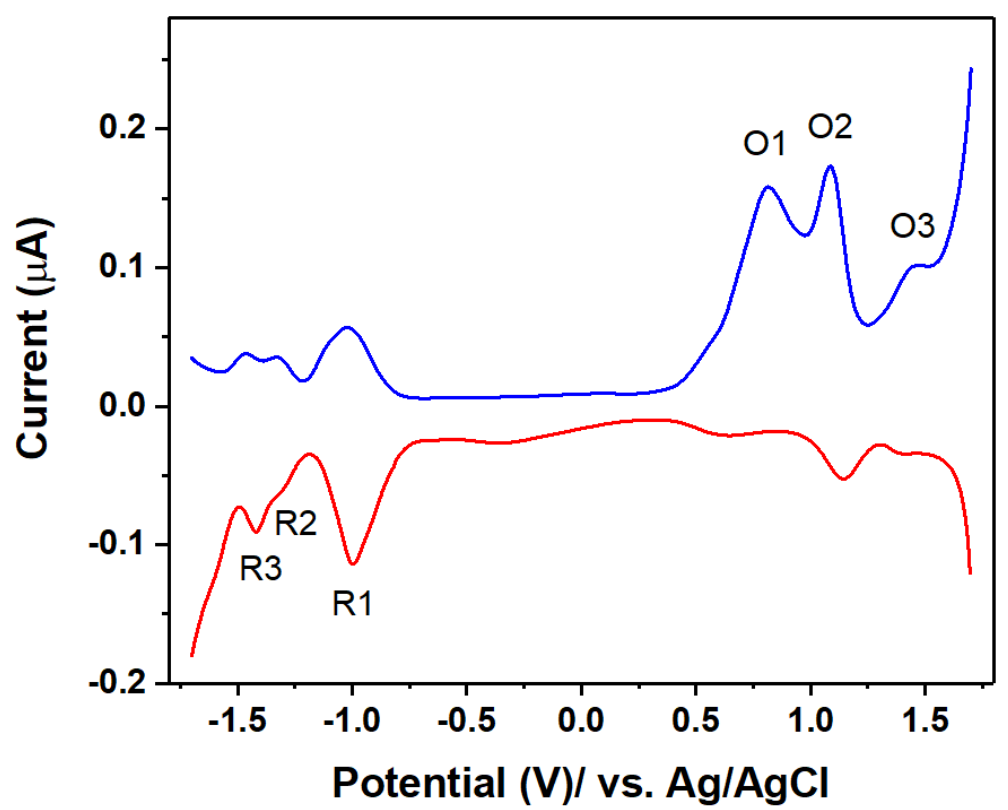

Figure S3. Differential pulse voltammetry of $1 \mathrm{mM} \mathrm{Au}_{12} \mathrm{Ag}_{13}$ in $1: 1 \mathrm{TOL} / \mathrm{ACN}$ solution at room temperature, with $0.1 \mathrm{M}$ TBAP (tetra-n-butylammonium perchlorate) as supporting electrolyte. The DPV was recorded at a Pt disk electrode $(\mathrm{d} \sim 0.5 \mathrm{~mm})$ as working electrode. $\mathrm{Ag} / \mathrm{AgCl}$ and $\mathrm{Pt}$ foil were used as reference and counter electrodes. A 20 min purging with Ar process was executed before measurement. 


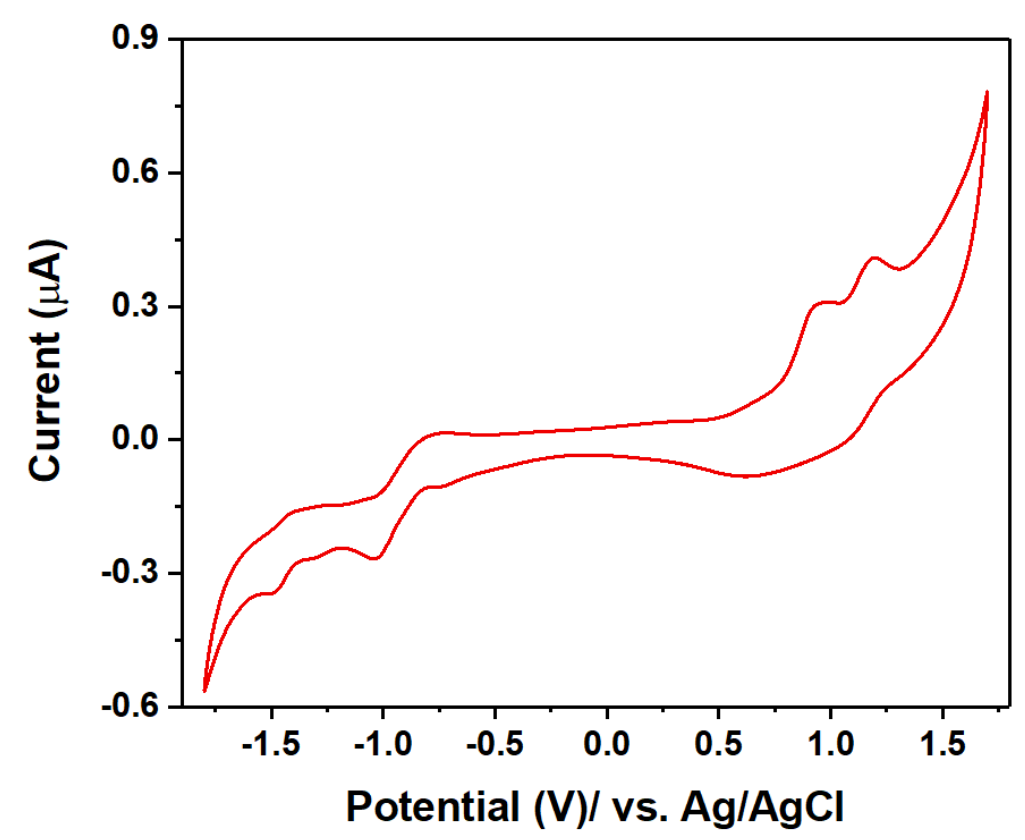

Figure S4. Cyclic voltammetry of $1 \mathrm{mM} \mathrm{Au}{ }_{12} \mathrm{Ag}_{13}$ in $1: 1 \mathrm{TOL} / \mathrm{ACN}$ solution at room temperature, with $0.1 \mathrm{M}$ TBAP as supporting electrolyte at a scan rate of $0.1 \mathrm{~V} / \mathrm{s}$. The $\mathrm{CV}$ was recorded at a Pt disk electrode ( $\sim 0.5 \mathrm{~mm}$ ) as working electrode. $\mathrm{Ag} / \mathrm{AgCl}$ and $\mathrm{Pt}$ foil were used as reference and counter electrodes. A 20 min purging with Ar process was executed before measurement.

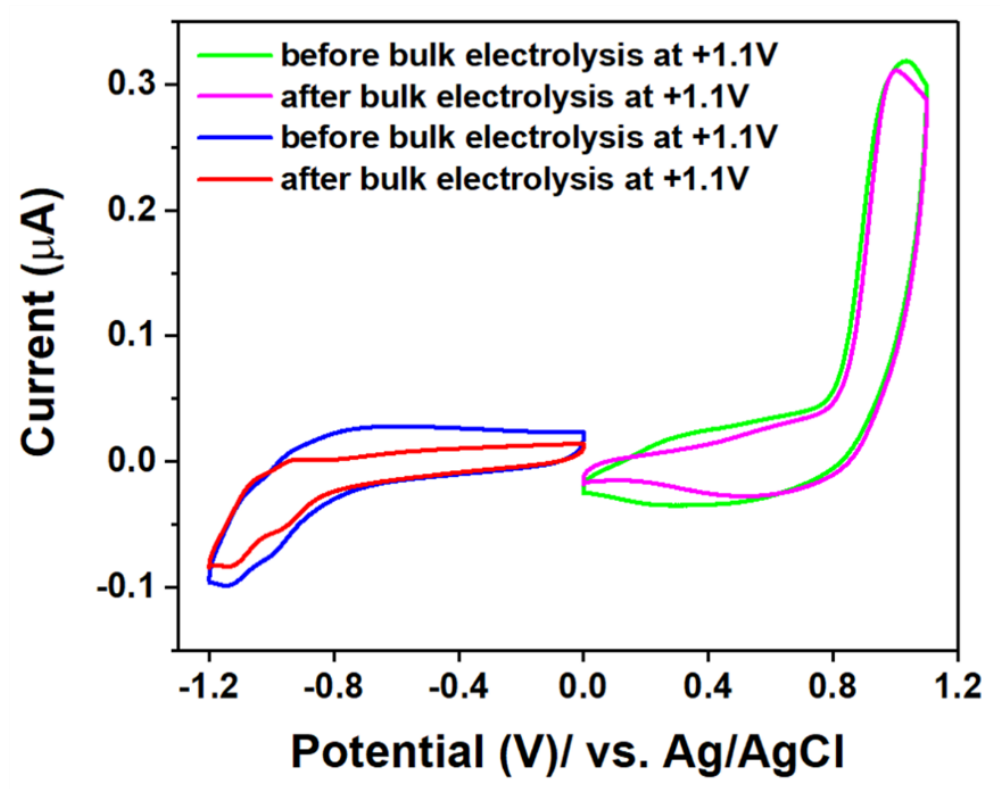

Figure S5. $\mathrm{CV}$ of $\mathrm{Au}_{12} \mathrm{Ag}_{13}$ on positive ( 0 to $1.1 \mathrm{~V}$ ) and negative ( 0 to $-1.2 \mathrm{~V}$ ) region before and after bulk electrolysis at $+1.1 \mathrm{~V}$. Both before electrolysis curves are control group (green and blue curve). After electrolysis, there is no big difference on either negative or positive region comparing to before electrolysis. 


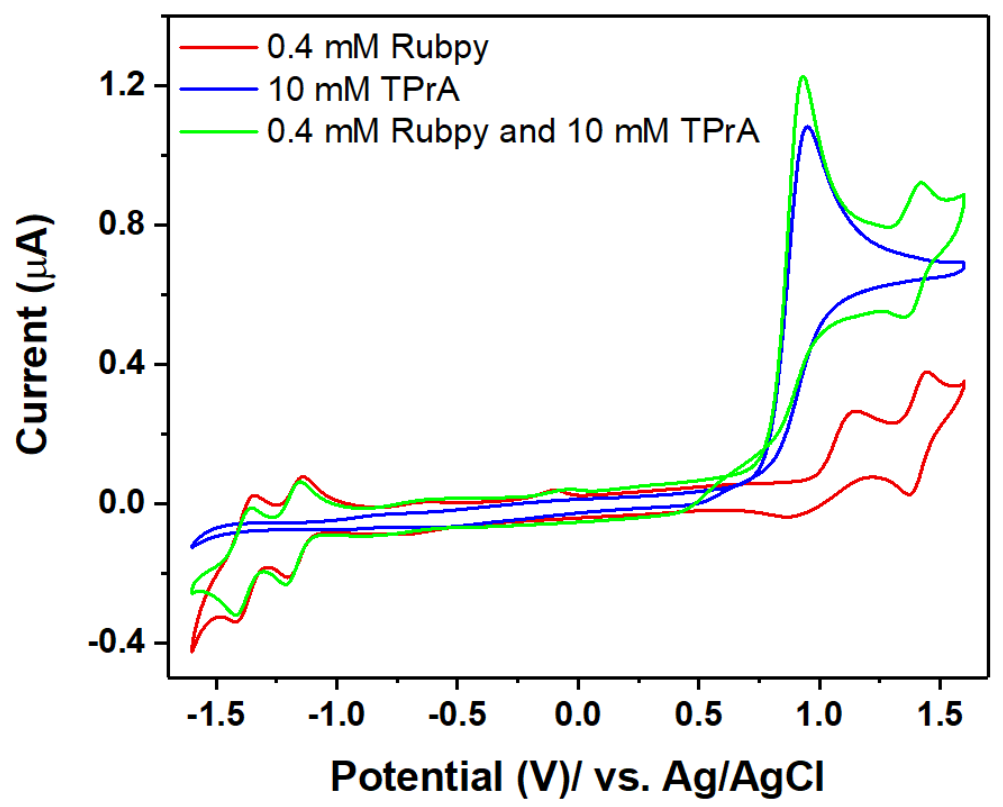

Figure S6. CV of Rubpy and TPrA in 1:1 TOL/ ACN with $0.1 \mathrm{M}$ TBAP at a $0.1 \mathrm{~V} / \mathrm{s}$ scan rate. The CV was recorded at a $\mathrm{Pt}$ disk electrode $(\mathrm{d} \sim 0.5 \mathrm{~mm})$ as working electrode. $\mathrm{Ag} / \mathrm{AgCl}$ and $\mathrm{Pt}$ foil were used as reference and counter electrodes. A 20 min purging with Ar process was executed before measurement.

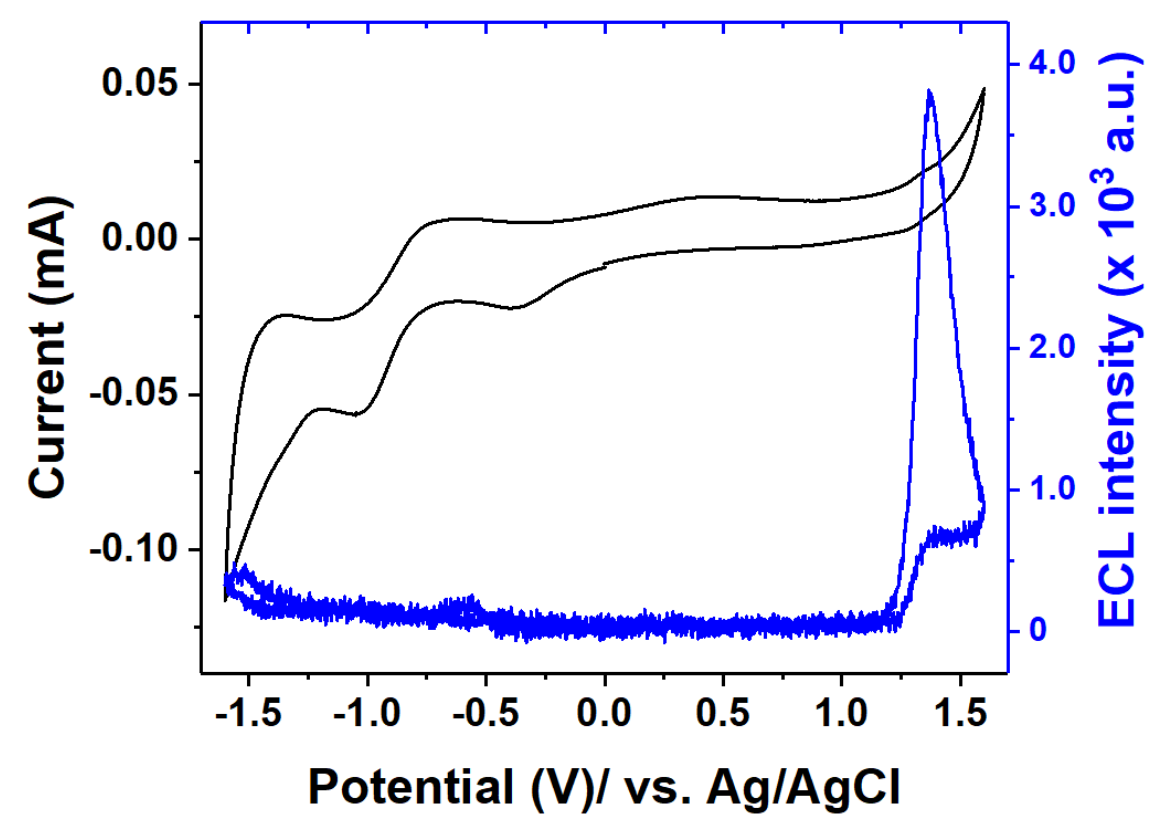

Figure S7. Cyclic voltammogram (left axis) and ECL-potential (right axis) curves for Rubpy-only. For CV and ECL measurements, a Pt mesh was used as working electrode in a $20 \mathrm{~mL}$ cuvette and purging with Ar. The purging process is continued to 20 min before test. The concentration of Rubpy is ca. $\sim 10 \mu \mathrm{M}$. The supporting electrolyte is $0.1 \mathrm{M}$ TBAP. Potential scan rate is $0.1 \mathrm{~V} / \mathrm{s}$. 


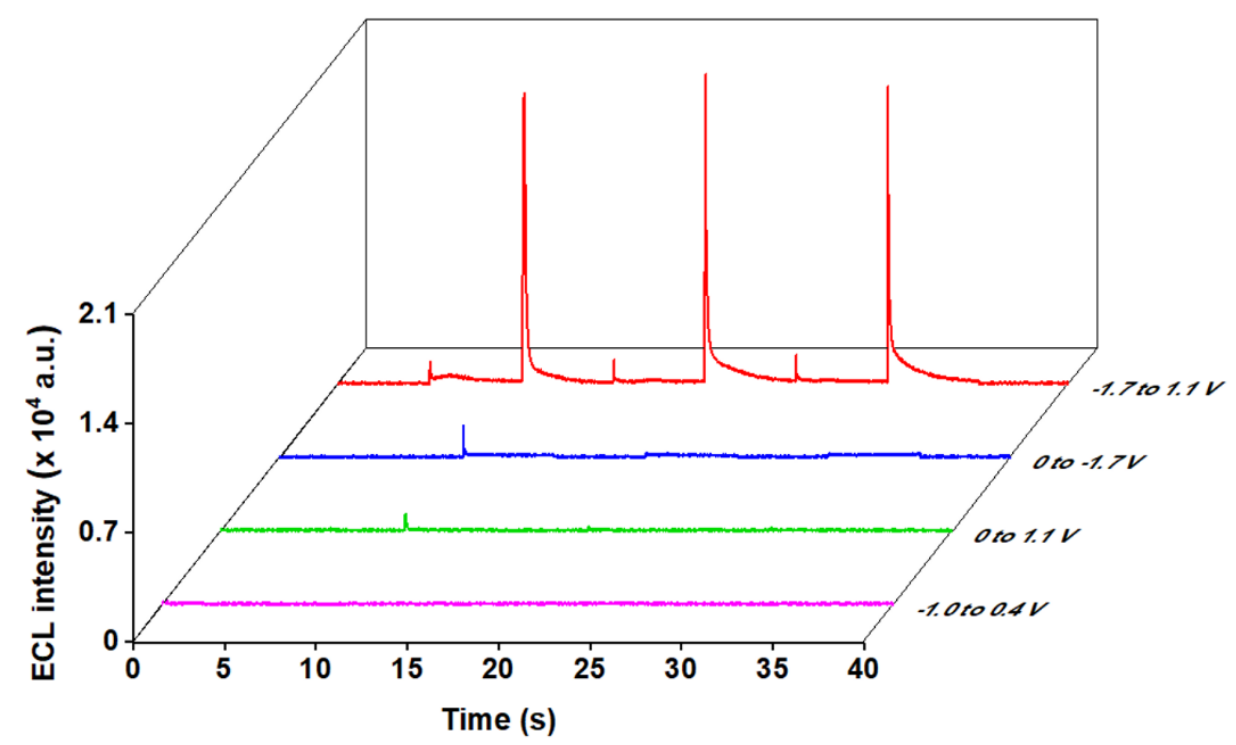

Figure S8. ECL profiles of $\left[\mathrm{Ag}_{\mathrm{x}} \mathrm{Au}_{25-\mathrm{x}}\left(\mathrm{PPh}_{3}\right)_{10}\left(\mathrm{SC}_{2} \mathrm{H}_{4} \mathrm{Ph}\right)_{5} \mathrm{Cl}_{2}\right]^{2+}(\mathrm{x} \leq 12)$ nanoclusters.

The only appreciable ECL signals (red curves) were recorded after the excitation of both HOMO and LUMO state via electron transfer reactions. Other curves are: LUMO activation (blue), HOMO activation (green) and none (pink. The electrode potential was held within HOMO \& LUMO states and insufficient to drive electron transfer reactions). The camera exposure time is $13.3 \mathrm{~ms}$ (same as one in $\mathrm{Au}_{12} \mathrm{Ag}_{13}$ tests). The concentration of $\left[\mathrm{Ag}_{\mathrm{x}} \mathrm{Au}_{25-\mathrm{x}}\left(\mathrm{PPh}_{3}\right)_{10}\left(\mathrm{SC}_{2} \mathrm{H}_{4} \mathrm{Ph}\right)_{5} \mathrm{Cl}_{2}\right]^{2+}(\mathrm{x} \leq 12)$ is ca. $\sim 10 \mu \mathrm{M}$ in 1:1 TOL:ACN with $0.1 \mathrm{M}$ TBAP electrolyte. The electrode potential was held for $5 \mathrm{~s}$ at the denoted potentials and stepped cyclically (3 cycles shown). No potential was applied in the first and final $5 \mathrm{~s}$.

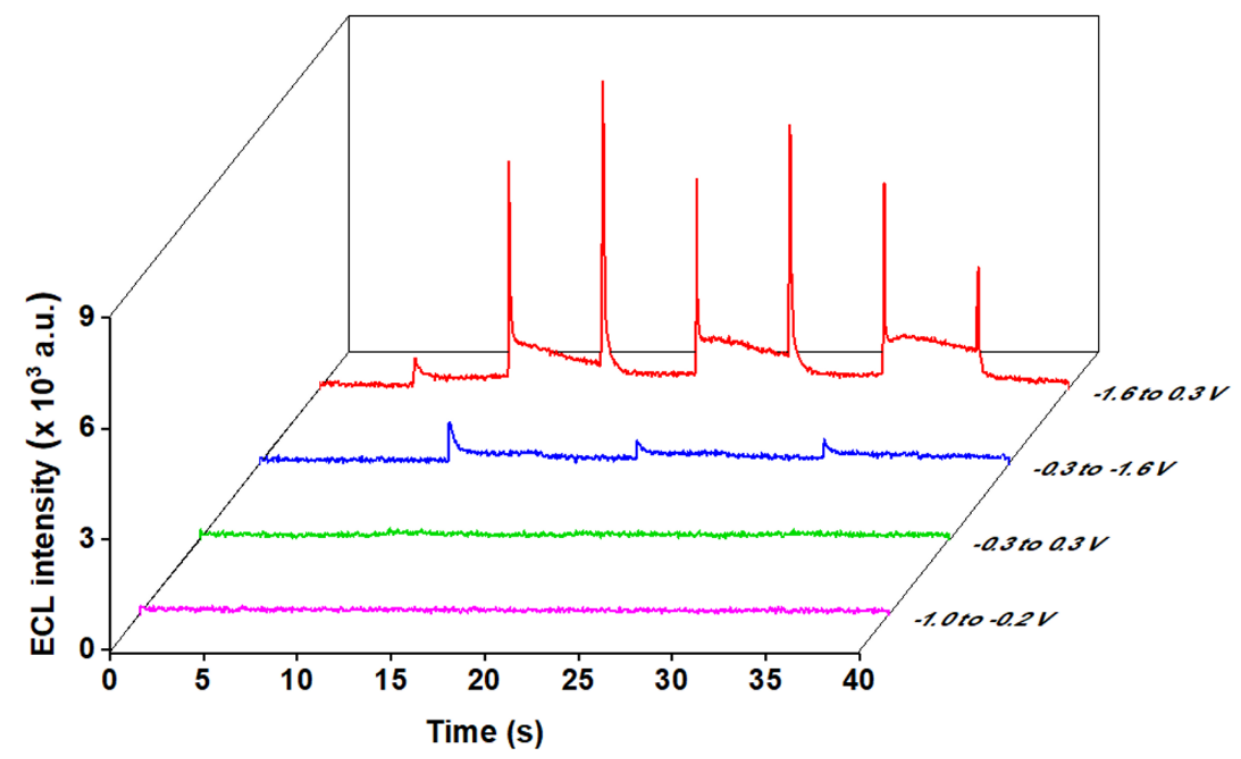

Figure S9. ECL profiles of $\mathrm{Au}_{25}\left(\mathrm{SC}_{2} \mathrm{H}_{4} \mathrm{Ph}\right)_{18}{ }^{-}$nanoclusters.

The only appreciable ECL signals (red curves) were recorded after the excitation of both HOMO and LUMO state via electron transfer reactions. Other curves are: LUMO activation (blue), HOMO activation (green) and none (pink. The electrode potential was held within HOMO \& LUMO states and insufficient 
to drive electron transfer reactions). Longer exposure time $(50 \mathrm{~ms})$ was used to collect the signal with adequate/comparable signal/noise ratio. The $\mathrm{Au}_{25}\left(\mathrm{SC}_{2} \mathrm{H}_{4} \mathrm{Ph}\right)_{18}{ }^{-}$concentration is ca. $\sim 10 \mu \mathrm{M}$ in $1: 1$ TOL:ACN with 0.1 M TBAP electrolyte. The electrode potential was held for $5 \mathrm{~s}$ at the denoted potentials and stepped cyclically ( 3 cycles shown). No potential was applied in the first and final $5 \mathrm{~s}$. 